\title{
Sensorless Control of Wound Rotor Synchronous Machines Based on High-frequency Signal Injection into the Stator Windings
}

\author{
Zhiguo Chen ${ }^{\star}$, Xianming Deng ${ }^{\dagger}$, Kun Huang ${ }^{\star}$, Wenhuan Zhen ${ }^{\star}$, and Lei Wang ${ }^{\star}$ \\ ${ }^{* \dagger}$ School of Information and Electrical Engineering, China University of Mining and Technology, Xuzhou, China
}

\begin{abstract}
This paper proposes a sensorless control approach for Wound Rotor Synchronous Machines (WRSMs) based on a high frequency voltage signal injection into the stator side $\mathrm{U}$ phase and VW line, respectively. Considering the machine itself as a rotor position sensor, the rotor position observer is established according to the principles of the rotary transformer. A demodulation method for the high frequency signal inducted in the rotor is proposed as well. Simulation and experimental results show that the proposed sensorless control approach has high performance and good practicability.
\end{abstract}

Key words: High frequency signal injection, rotor position detection, sensorlss control,wound rotor synchronous machine

\section{INTRODUCTION}

For high performance synchronous motor vector control systems, the exact rotor position is necessary. The rotor position is normally detected by mechanical sensors such as photoelectric encoders or resolves. However, these mechanical sensors bring a lot problems to speed control systems: (1) the additional devices of mechanical sensors increase the cost of systems; (2) the mechanical sensors are installed in the shaft, and concentricity affects the installation. As a result, improper installation decreases the measurement precision; (3) the installation of mechanical sensors increases the volume on the shaft. This in turn makes the system more complex and reduces the mechanical robustness of the system; (4) the system accuracy is affected by environmental conditions, since mechanical sensors are sensitive to high temperature humidity and other harsh environmental conditions; (5) the operation and maintenance of the system become more difficulty.

To overcome these shortcomings, since the 1970s, more and more scholars have been conducting research on identification methods without mechanical sensors, i.e., sensorless control. At present, most of the sensorless control methods are based on

\footnotetext{
Manuscript received Nov. 8, 2012; revised Mar. 19, 2013 Recommended for publication by Associate Editor Jung-Ik Ha. ${ }^{\dagger}$ Corresponding Author: xmdeng3883023@hotmail.com Tel: +86-130-1398-1898, China University of Mining and Technology *School of Information and Electrical Engineering, China University of Mining and Technology, China
}

permanent magnet synchronous motors (PMSMs) or induction motors (IMs), while wound rotor synchronous machines (WRSM) are rarely mentioned. The sensorless control methods presented in the literature are overwhelming. These methods include state observers based on advanced models ${ }^{[1-3]}$, Kalman filter based estimators ${ }^{[4-6]}$ and estimation based on high-frequency signal injection ${ }^{[7]}$. Injecting a high frequency signal into the rotor side is used in paper ${ }^{[8]}$, but it is difficult to inject a high frequency signal into the rotor. In addition, the detected high-frequency signal from the stator is relatively small. Therefore, the sensorless performance is not good enough. This paper proposes a sensorless control method for WRSMs based on a high frequency voltage signal injection into the stator side U phase and VW line, respectively. Through the proposed proper demodulation of the obtained high frequency signal in the rotor, the high resolution sensorless position and speed are realized.

\section{WRSM SENSORLESS CONTROL PRINCIPLE}

The basic idea behind sensorless detection is regarding the WRSM itself as a rotor position sensor. As a result, the external mechanical sensor can be removed. Combined with the electromagnetic relations of a machine, the position and speed can be calculated according to the basic voltage and current information.

Fig. 1 shows the rotor position and speed detection circuit of a synchronous motor based on a high-frequency signal 


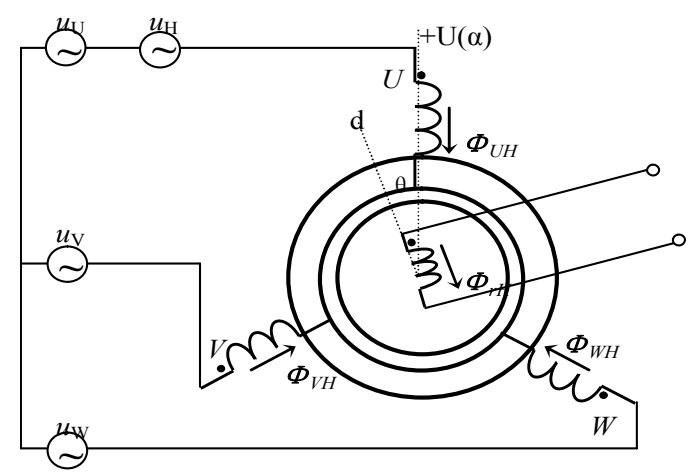

Fig. 1. Rotor position and speed detection circuit of the synchronous motor based on high-frequency signal injection to the stator.

injection to the stator, where the three-phase symmetrical windings distribute the stator and the field windings on the rotor. From the principle of the sensorless detection, the WRSM is regarded as a rotary transformer, where the input winding is the stator winding and the output is the field winding. A high-frequency signal is injected into the stator winding and the output signal is detected from the field winding, which contains the rotor position and speed information. The high-frequency signal can be injected into phase $\mathrm{U}$ or through phase $\mathrm{V}$ to phase $\mathrm{W}$, i.e. the $\mathrm{VW}$ line. The method works as follows.

\section{A. Analysis of the High-Frequency Signal Injection to Phase $U$}

This will produce a corresponding high-frequency pulse magnetic field referred to as $\Phi_{\mathrm{UH}}=\Phi_{\mathrm{m}} \sin \omega_{\mathrm{H}} \mathrm{t}$ on the axis of phase $U$ (that is the $U$-axis or $\alpha$-axis) when injecting a certain high-frequency signal into phase $U$. The amplitude of the field changes over time. When the rotor position modulates, the high-frequency magnetic flux of the rotor winding changes accordingly. The angle between the d-axis of the rotor ( $\mathrm{N}$-axis of the rotor) and the positive U-axis is supposed to be $\theta$ (electrical angle). Then the flux linkage of the stator winding and the rotor winding are as follow:

$$
\left\{\begin{array}{l}
\phi_{U H}=\phi_{m} \cdot \sin \omega_{H} t \\
\phi_{r H}=\phi_{m} \cdot \cos \theta \cdot \sin \omega_{H} t \\
\phi_{V H}=-0.5 \phi_{m} \cdot \sin \omega_{H} t \\
\phi_{W H}=-0.5 \phi_{m} \cdot \sin \omega_{H} t
\end{array}\right.
$$

Fig. 2 shows a space-vector diagram of the high-frequency magnetic field.

The electromotive force (EMF) of the rotor winding based on the transformer principle is obtained, as shown in Figure 1.

$$
\left\{\begin{array}{l}
e_{U H}=\omega_{H} N_{s} \phi_{m} \cdot \sin \left(\omega_{H} t-90^{\circ}\right) \\
e_{r H}=\omega_{H} N_{r} \phi_{m} \cos \theta \cdot \sin \left(\omega_{H} t-90^{\circ}\right) \\
e_{V H}=-0.5 \omega_{H} N_{s} \phi_{m} \cdot \sin \left(\omega_{H} t-90^{\circ}\right) \\
e_{W H}=-0.5 \omega_{H} N_{s} \phi_{m} \cdot \sin \left(\omega_{H} t-90^{\circ}\right)
\end{array}\right.
$$

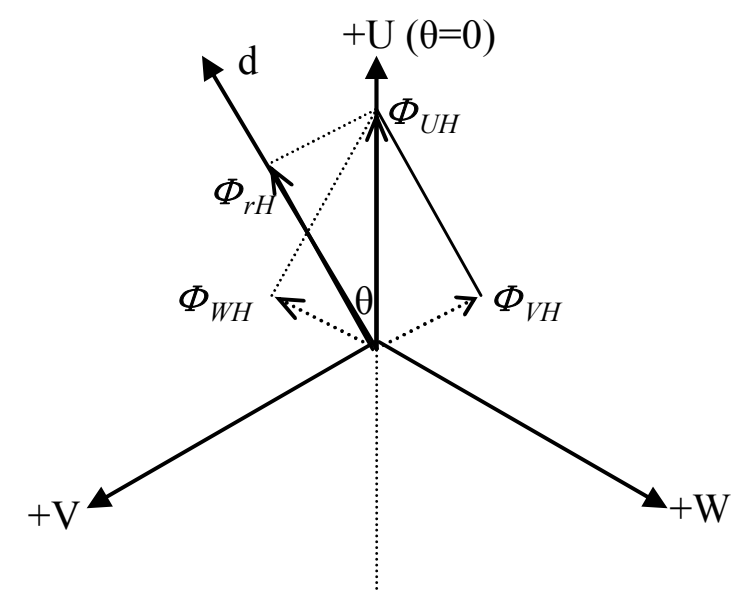

Fig. 2. Space-vector diagram of the high-frequency magnetic field.

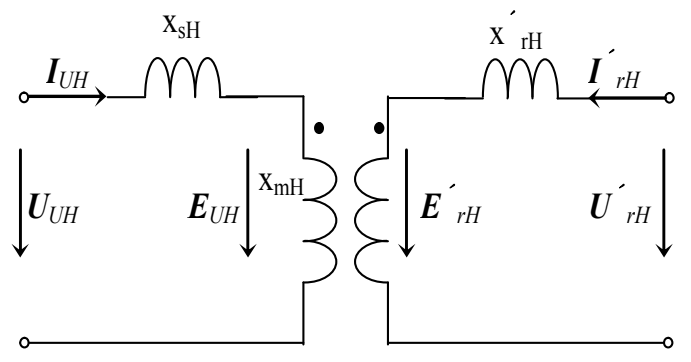

Fig. 3. Equivalent circuit of high-frequency signal injection.

Where $\mathrm{N}_{\mathrm{r}}$ is the equivalent turns of the rotor winding, $\mathrm{N}_{\mathrm{s}}$ is the equivalent turns of the stator winding, and $\mathrm{k}=\mathrm{N}_{\mathrm{s}} / \mathrm{N}_{\mathrm{r}}$ is the equivalent turns ratio between the stator and the rotor.

Figure 3 shows the equivalent circuit of the high-frequency signal injection. Using the analysis method of the transformer, the equivalent circuit is obtained, where the high-frequency reactance is much larger than the winding resistance, and the winding resistance can be neglected. The physical quantities of the rotor side can be converted to the stator windings based on the winding translation in the electrical motor, where $\mathrm{x}_{\mathrm{SH}}$ is the leakage impedance of the stator winding, and $\mathrm{x}_{\mathrm{rH}}$ is the converted leakage impedance of the rotor winding.

Figure 3 provides the positive direction for the nonsalient pole synchronous motor, and the voltage equation corresponding to the high-frequency signal is obtained as:

$$
E_{U H}=\frac{x_{m H}}{x_{s H}+x_{m H}} U_{U H}=k_{x} U_{U H}
$$

Where $\mathrm{k}_{\mathrm{x}}$ is the distribution voltage coefficient of the stator winding.

The voltage effective value of the rotor winding can be calculated according to Equation(3). If the leakage impedance is ignored Equation(4) can be obtained from Equation(2) and Equation(3): 


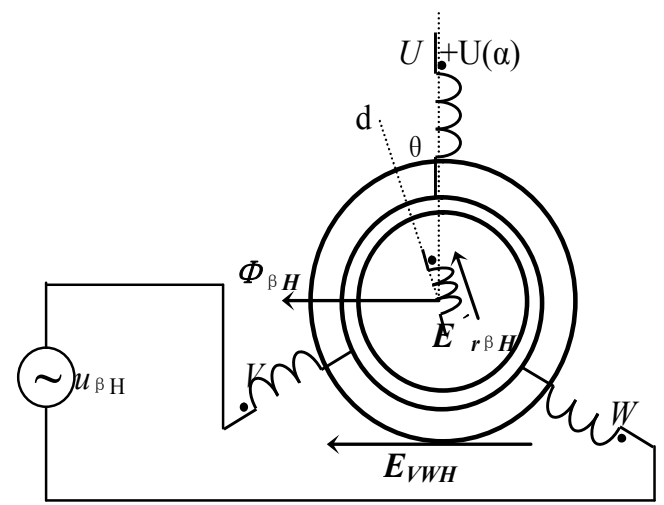

Fig. 4. The circuit diagram with high-frequency signal injection into VW line of the stator.

$$
\left\{\begin{array}{l}
U_{U H}=4.44 f_{H} N_{s} \phi_{m} \\
U_{r H}^{\prime}=U_{U H} \cos \theta \\
U_{V H}=0.5 U_{U H} \\
U_{W H}=0.5_{U H}
\end{array}\right.
$$

As shown in Equation(4), by comparing the stator with the rotor, it can be seen that phase and frequency of the high-frequency voltage are the same, except for the difference in the amplitude.

Then Equation(4) can be used to calculate the rotor position.

\section{B. Analysis of the high-frequency signal injection between phase $V$ and phase $W$}

Figure 4 shows a circuit diagram of the high-frequency signal injection into the VW line of the stator.

This will produce a corresponding high-frequency pulse magnetic field on the axis perpendicular to the positive phase $U$ (axis- $\beta$ ) when injecting a certain high-frequency signal $\mathrm{u}_{\beta \mathrm{H}}$, with a magnitude of $U_{\beta H}$ and a frequency of $\omega_{\beta H}$ through phase $\mathrm{V}$ to phase $\mathrm{W}$. The magnetic field will produce an inductive EMF in the rotor winding and line VW. In order to simplify the analysis, the rotor EMF is converted to the stator side and the same signal as that of phase $U$ is injected. Assuming that the rotor $\mathrm{d}$-axis deviates from the positive axis of the phase $U$ electrical angle, the EMF relationship between line VW and the rotor winding is obtained as follows:

$$
\left\{\begin{array}{l}
E_{V W H}=-U_{\beta H} \\
E_{r \beta H}^{\prime}=-U_{\beta H} \sin \theta
\end{array}\right.
$$

The output voltage of the rotor winding can be obtained from Equation (5) if the leakage impedance is ignored:

$$
U_{r \beta H}^{\prime}=U_{\beta H} \sin \theta
$$

It can be found from Equation (4) and Equation (6) that the output voltage of the rotor winding and the rotor position angle follow the cosine law when injecting a high-frequency signal into phase U. In addition, they follow the sine law when injecting a high-frequency signal through phase $\mathrm{V}$ to phase $\mathrm{W}$. It can be seen that by using the method of rotor position detection based on a high-frequency signal injection into the stator, a high-frequency signal can be injected into phase $U$ or line VW to get the rotor position with Equation (4) and (6). In addition, a different high-frequency signal can be injected into phase $\mathrm{U}$ and line VW at the same time to calculate the rotor position. Two signals with a different frequency or phase are chosen. Then the output voltage includes sine and cosine quantities. The two signals can be isolated by filtering, and it is possible to calculate rotor position and speed conveniently.

C. Calculation of the synchronous motor rotor position and speed based on the stator high frequency signal injection

After obtaining the initial position angle $\theta$ with the above method, the value of the angle can be calculated using Equation (4) as follows:

$$
\theta=\arccos \left(\frac{U_{r H}^{\prime}}{U_{U H}}\right)
$$

The mechanical speed of the rotor, $\mathrm{n}_{\mathrm{r}}$ can be acquired by calculating the derivative of the position angle.

$$
n_{r}=\frac{9.55}{p} \times \frac{d \theta}{d t}
$$

Where $\mathrm{p}$ is the number of pole-pairs. The electrical angle should be divided by $\mathrm{p}$ before the derivative when calculating the mechanic speed, because $\theta$ is $p$ times the mechanic angle.

A different high-frequency signal can be injected into phase $\mathrm{U}$ and line VW (i. e., $\alpha$-axis and $\beta$-axis) at the same time. Then by using filters with the phase-locked loop (PLL) method it is possible to separate the two inductive signals and calculate the rotor position and speed from the sine and cosine components conveniently ${ }^{[9-11]}$. The two signals have different frequencies and different phases.

Figure 5 presents the principle of the PLL. The PLL mainly includes a voltage-controlled oscillator (VCO), a phase comparator and a low pass filter (LPF). By comparing the external input $u_{i}$ with the output of the VCO $u_{o}$ with a phase comparator, and by using the LPF to process the error signal $u_{e}$, a signal $u_{d}$ can be obtained to control the VCO. The control signal $u_{o}$ can make the output phase and the input phase a relative constant and it can make their frequencies the same. As a result, the input frequency can be measured ${ }^{[12-14]}$. Here a method according to the WRSM based on the self-detection of a PLL to estimate the rotor position and speed has been proposed, as shown in Figure 6.

From Figure 6:

$$
\begin{aligned}
\theta_{r}=\frac{\omega_{r}}{s}, \theta_{r} & =\frac{\omega_{r}^{\prime}}{s}, \text { based on the feedback control theory: } \\
\frac{\theta_{r}^{\prime}}{\theta_{r}} & =\frac{\frac{1}{s}\left(K_{P}+\frac{K_{I}}{s}\right)}{1+\frac{1}{s}\left(K_{P}+\frac{K_{I}}{s}\right)}=\frac{\left.K_{P} s+K_{I}\right)}{s^{2}+K_{P} s+K_{I}}
\end{aligned}
$$

which is equal to 


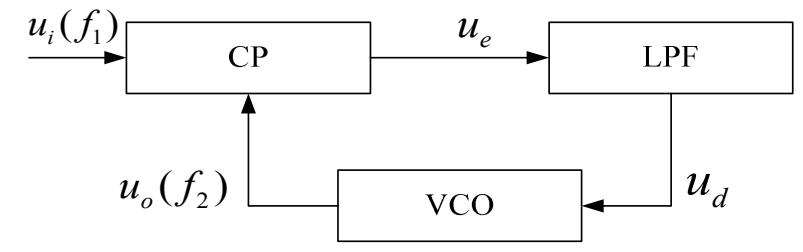

Fig. 5. Principle of phase-locked loop (PLL)

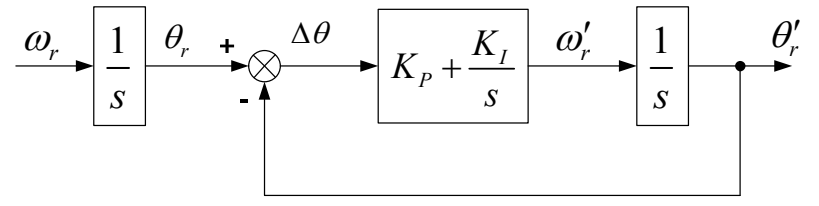

Fig. 6. Principle of rotor position estimation based on PLL.

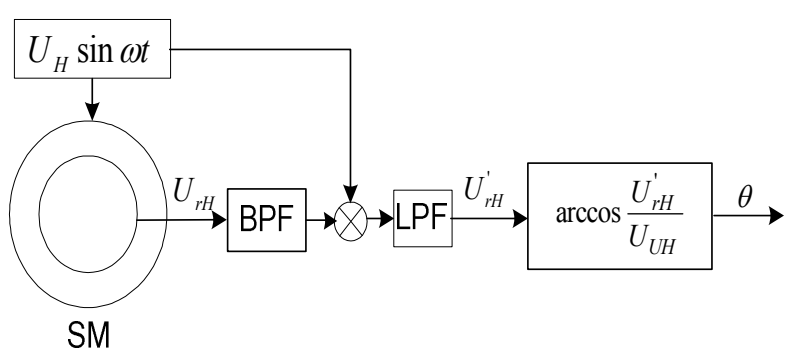

Fig. 7. Block diagram of rotor position detection based on high-frequency signal injection into the stator

$$
\frac{\omega_{r}^{\prime}}{\omega_{r}}=\frac{\frac{\omega_{r}^{\prime}}{s}}{\frac{\omega_{r}}{s}}=\frac{\left.K_{P} s+K_{I}\right)}{s^{2}+K_{P} s+K_{I}} .
$$

The transfer function from the electrical angular speed $\omega$ to the estimated electrical angular speed $\omega_{r}$ can be shown as a second-order system.

In (10), the proportion and integral coefficient are $K_{P}$ and $K_{I}$ respectively and they are designed based on the response characteristics of the second-order system. The output of the regulator is the estimated electrical angular speed $\omega_{r}^{\prime}$.

\section{Simulation ANALYSIS OF POSITION AND SPEED DETECTION BASED ON A HIGH FREQUENCY SIGNAL INJECTION INTO THE STATOR}

Fig. 7 shows a block diagram of the rotor position detection based on a high-frequency signal injection into the stator. After injecting a high-frequency $\mathrm{AC}$ voltage signal $U_{H} \sin \omega_{H} t$ into phase $\mathrm{U}$, the HF voltage signal of the rotor through a high pass filter (HPF) referred to as $U_{r H}=U_{U H} \sin \omega_{H} t \cos \theta$ is obtained. In order to get the rotor position angle $\theta$, multiply $U_{r H}$ by the injection signal and the LPF. Then $U_{r H}^{\prime}=U_{U H} \cos \theta$ is obtained.

Based on the above analysis and using Matlab/Simulink, a simulation analysis was carried out for the WSRM position and speed detection based on the stator high frequency signal injection. To control the motor based on the vector control model, and to observe the rotor position based on a high frequency signal injection, the simulation motor parameters are listed in Table I in the Appendix. They are the same as the parameters previously mentioned. The initial state of the motor is at standstill, a rated speed of $48 \mathrm{r} / \mathrm{min}$ is given at $1.5 \mathrm{~s}$ and the rated load is set to $4.5 \mathrm{~s}$. The high frequency signal is $50 \mathrm{~V}$, $1000 \mathrm{~Hz}$. The parameters of the tested WRSM are presented in Table I in the Appendix. For the convenience of calculation, the current value has been expressed as a per-unit value.

Fig. 8 shows the rotor position detection based on a high-frequency signal injection into the stator at startup, where the first $1.5 \mathrm{~s}$ is the excitation process where the rotor is kept still, the rotor begins to speed up at $1.5 \mathrm{~s}$ when a given speed is added, and the speed arrives at the rated speed and is kept steady until $4 \mathrm{~s}$. The three figures show: the inductive high frequency current signal in the rotor side, the envelope of the rotor position after demodulation, and the rotor position angle (the red line is the actual value and the blue line is the observation value).

From the figure it can be seen that the rotor side can detect the inductive high frequency signal well at the start and during the speed up process. The envelope of the rotor position is basically a cosine wave with the same amplitude. The amplitude of the rotor high frequency voltage changes over the rotor position and follows the cosine law. The observed rotor position can follow the actual position precisely.

Figure 9 shows the rotor position detection based on a high-frequency signal injection into the stator with a step load, where the first $3.5 \mathrm{~s}$ is the excitation and speed up process, after $3.5 \mathrm{~s}$ the motor is kept steady at the rated speed, at $4.5 \mathrm{~s}$ the motor is suddenly given a rated load, and the observation block works at 3s. In Figure 9, the three figures show: the high frequency current in the rotor side, the envelope of the rotor position after demodulation, and the rotor position angle (the red line is the actual value and the blue line is the observation value).

This is similar to the startup process where the inductive high frequency signal can be detected well in the rotor side during a step load, and it can follow the actual position. The rotor position estimation is robust to load disturbances. Step loads scarcely effect the rotor position estimation.

From the above simulation results, it can be seen that the performance of the sensorless control of a WRSM based on a stator high frequency signal injection is really good. However, there are still disadvantages. The speed is a derivative of the rotor position angle, so it produces a large error when there is a small disturbance. In addition, this method only injects a high frequency signal to one phase, which may affect the detection precision and filter parameters. This in turn may lead to difficulty in realizing vector control. 


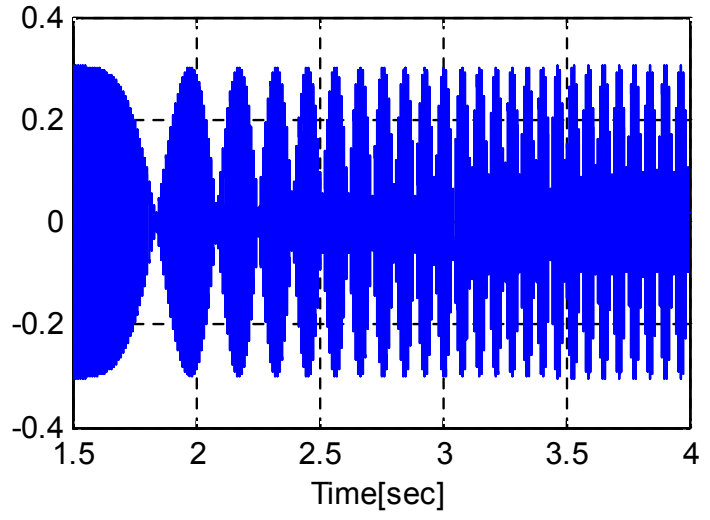

(a) inductive high frequency current signal in the rotor side

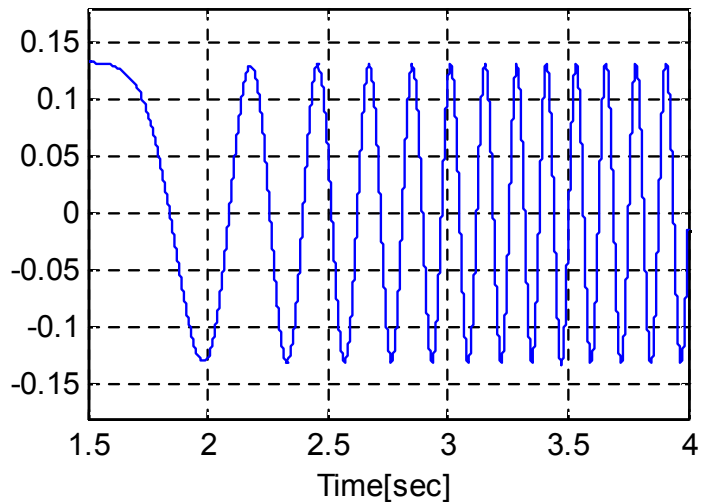

(b) envelope of rotor position after demodulation

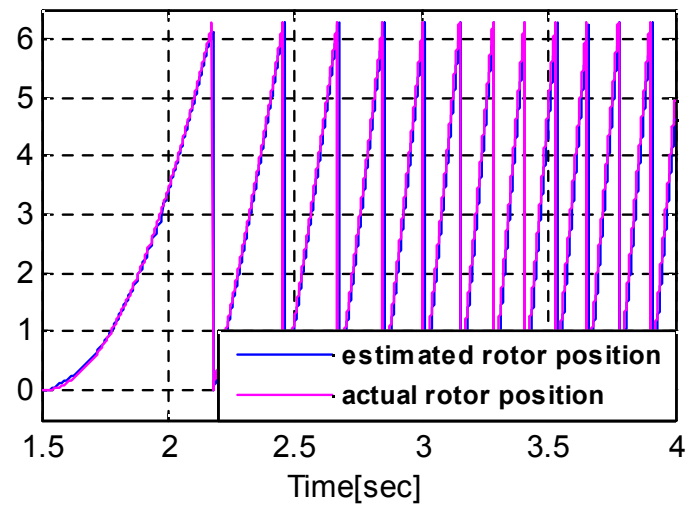

(c) rotor position angle

Fig. 8. Rotor position detection based on high-frequency signal injection into the stator at startup

In order to solve the problems caused by the fact that a single signal is easily affected by current transients, the previously mentioned PLL is used to obtain a more steady and accurate speed.

\section{SimUlation OF SENSORLESS SYNCHRONOUS MOTOR VECTOR CONTROL BASED ON A HIGH FREQUENCY SIGNAL INJECTION INTO THE STATOR}

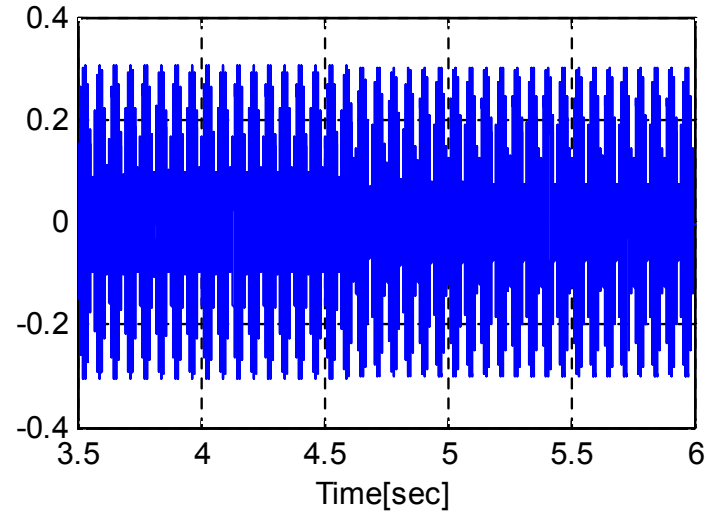

(a)

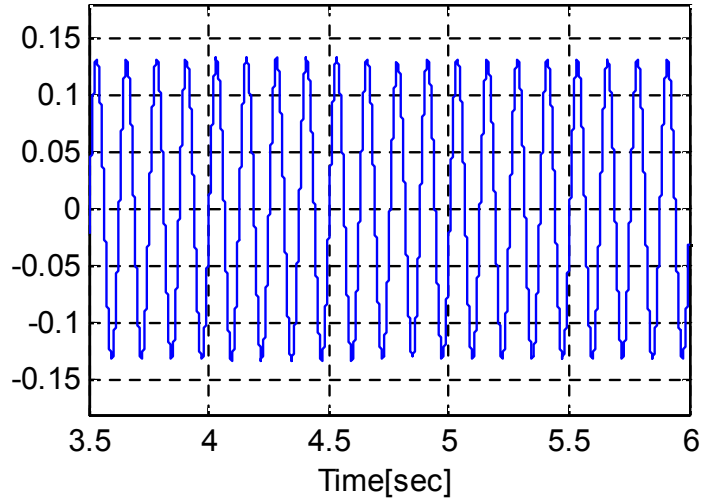

(b)

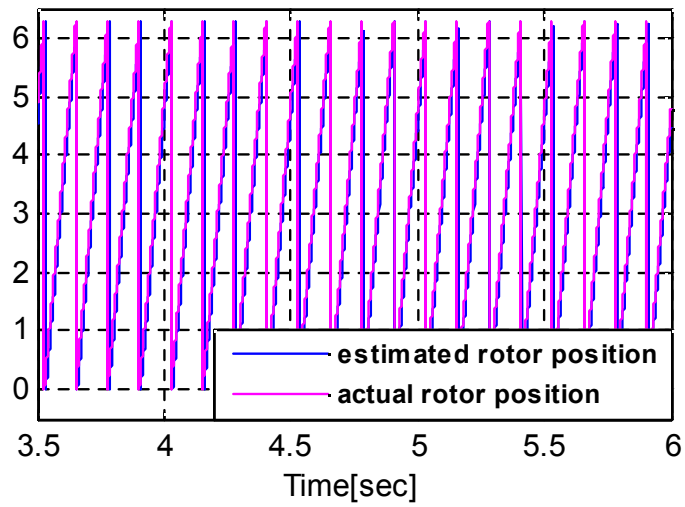

(c)

Fig. 9. Rotor position detection based on high-frequency signal injection into the stator with step load.

In this section, Figure 10 shows a sensorless detection diagram of the rotor position and speed based on a high-frequency signal injection into the stator. After injecting the high frequency signals $U_{H} \sin \omega_{H} t$ into phase $\mathrm{U}$ ( $\alpha$-axis) and $U_{H} \cos \omega_{H} t$ which has the same amplitude and frequency into line VW, the inductive high frequency signal in equation(11) is obtained after the HPF.F

$$
U_{r H}=U_{U H} \sin \omega_{H} t \cos \theta+U_{U H} \cos \omega_{H} t \sin \theta
$$




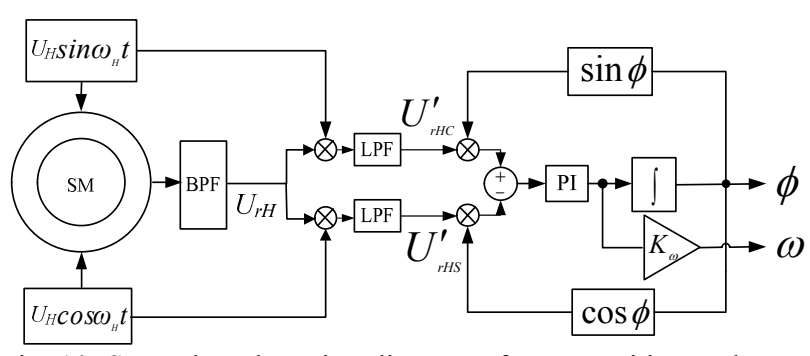

Fig. 10. Sensorless detection diagram of rotor position and speed based on high-frequency signal injection into the Stator.

Multiply the signal with the injected high-frequency signals $U_{H} \sin \omega_{H}$ and $U_{H} \cos \omega_{H} t$ and the LPF, respectively. $U_{r H C}^{\prime}=U_{U H} \cos \theta$ and $U_{r H S}^{\prime}=U_{U H} \sin \theta$ are obtained and the error signal can be constructed.

$$
\begin{aligned}
\varepsilon \Delta \theta_{e} & =U_{U H} \cos \theta \sin \phi-U_{U H} \sin \theta \cos \phi \\
& =U_{U H} \sin (\phi-\theta) \\
& \cong \varepsilon \Delta \theta_{r e}
\end{aligned}
$$

The estimated rotor position and speed can be obtained by the Phase-Lock-Loop (PLL) observer.

Similarly, to simulate with the above model of vector control, detect the position and speed as feedback signals to realize the sensorless vector control. The parameters of the motor in the simulation are the same with the ones above. The motor's initial state is at standstill, a rated speed $48 \mathrm{r} / \mathrm{min}$ is given at 1.5 $\mathrm{s}$, and the rated load is given at $4.5 \mathrm{~s}$. The high frequency signal is $50 \mathrm{~V}, 1000 \mathrm{~Hz}$.

Figure 11 shows the vector control waveform without speed sensors based on a high-frequency signal injection into the stator. Where Figure 11(a) is the envelope of the rotor position after demodulation (the red line is cosine and the blue line is sine); Figure 11(b) is the speed response (the red line is the given value and the blue line is the observation value); and Figure 11(c) is the actual position of the rotor (the red line) and the observation value (the blue line). Figure 12 shows the error of the speed observation of the sensorless vector control based on a high-frequency signal injection into the stator.

Figure 11(a) shows that the proposed method is good at demodulating the inductive high frequency signal in the rotor. Figure 11(b) shows that it is easy to follow a given speed and realize sensorless vector control even under a step load. In Figure 11(c), the estimated position follows the actual position with good dynamic performance. The first $1.5 \mathrm{~s}$ is the excitation process and the rotor is kept still. It is also shown that the initial estimated position is zero degrees.

In Figure 12, it can be seen that there is small error between the estimated and actual speed in the dynamic process after the motor starts. This error is within $\pm 0.3 \mathrm{r} / \mathrm{min}$, and it is nearly 0 in the steady state. It can be seen that the proposed method can realize sensorless vector control with a high precision.

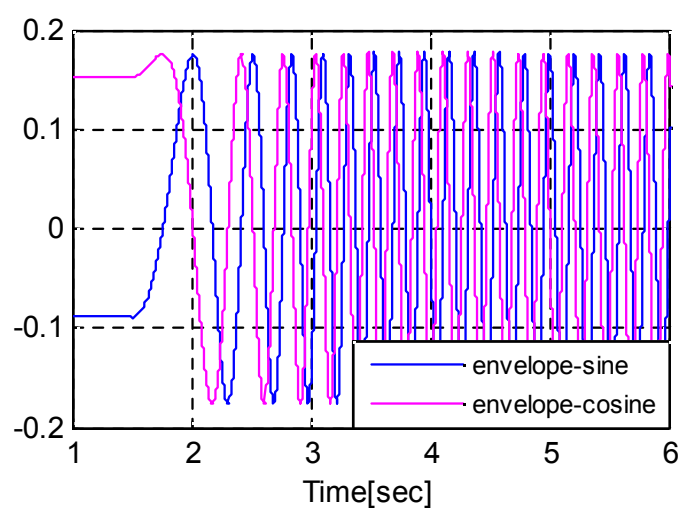

(a)

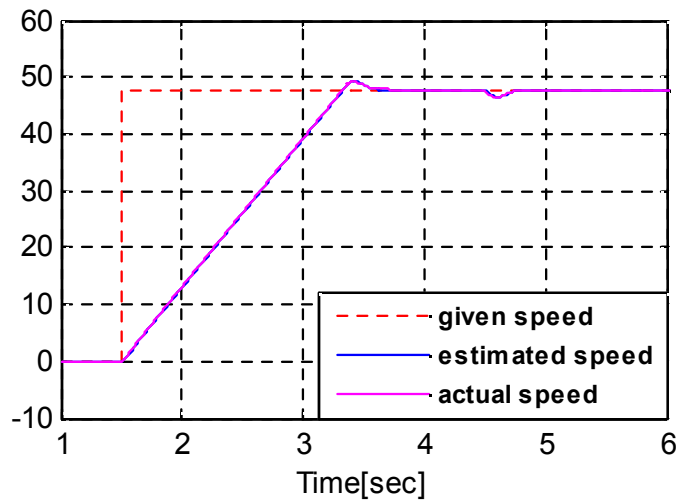

(b)

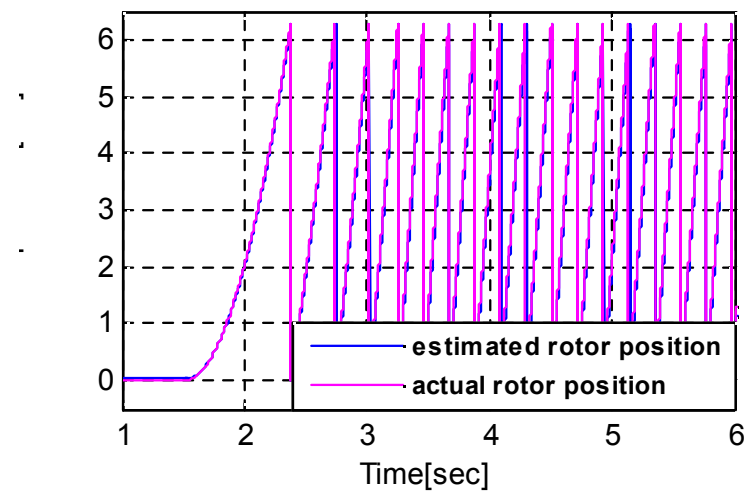

(c)

Fig.11. Vector control waveform without speed sensors based on high-frequency signal injection into the stator.

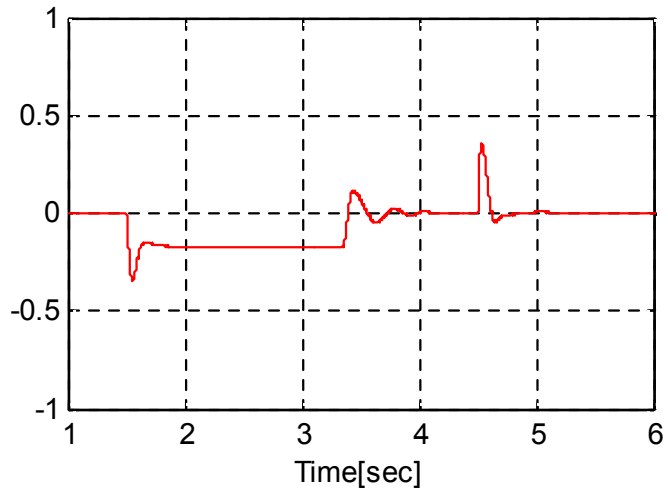

Fig.12. Error of speed observation of sensorless vector control based on high-frequency signal injection into the stator. 


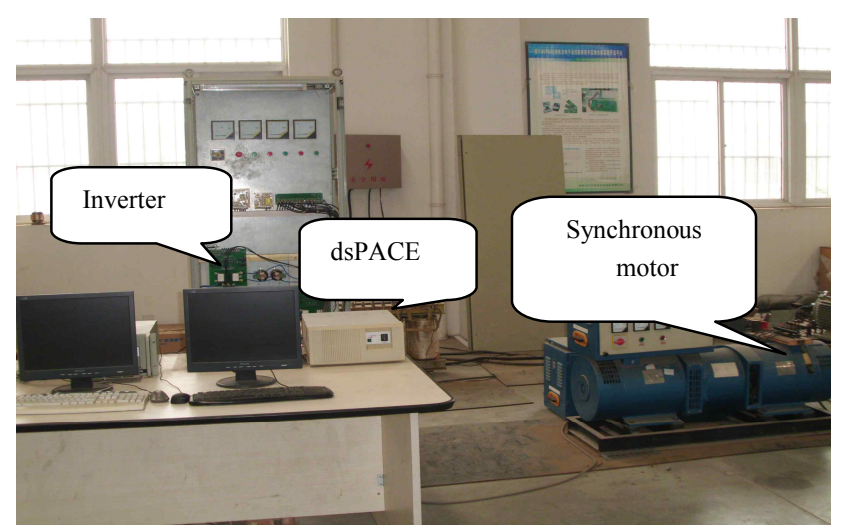

Fig. 13. Experiment equipment of synchronous motor.

\section{ANALYSIS OF THE EXPERIMENT ON SENSORLESS CONTROL WITH A HIGH FREQUENCY INJECTION}

In order to prove the correctness and feasibility of the proposed method with a high frequency injection, an experiment was designed with dSPACE and the power conversion cabinet to control a WRSM. The voltage and current sensors are Hall sensors, the synchronous motor is a 4 pole small power motor. The parameters of the WRSM are listed in Table II in the Appendix. The experimental equipment for the synchronous motor is shown in Fig.13.

In order to estimate speed conveniently and reduce the interference on speed estimation from high frequency signal fluctuations, the method of high frequency injection presented in the simulation (section III) was used in this experiment. A sine high frequency signal $U_{H} \sin \omega_{H} t$ was injected into the motor $\alpha$-axis and a cosine high frequency signal $U_{H} \cos \omega_{H} t$ was injected into the $\beta$-axis. Due to the limitations of the experimental conditions, the high frequency signal was set to $200 \mathrm{~Hz}, 40 \mathrm{~V}$. The inductive high frequency signal in the rotor side is detected by Hall sensors and sent to dSPACE. The high frequency signal is then filtered and demodulated in dSPACE and the envelopes of the sine and cosine signals are obtained. The rotor speed and position are then calculated by the PLL. Finally, the rotor information is used in the closed loop control. The experimental results are shown in Figure 14, Figure 15, and Figure 16. For the convenience of calculation, the current value has been expressed as a per-unit value.

Figure 14 shows the sensorless control results based on a high-frequency signal injection into the stator with a stable speed of $150 \mathrm{r} / \mathrm{min}$. The estimated rotor position and speed are used as feedback signals to control the motor. Figure 14 (a) shows the envelope of the rotor position after demodulation (the red one is cosine envelope and the blue one is the sine envelope); Figure 14 (b) shows the rotor speed; and Figure 14 (c) shows the rotor position.

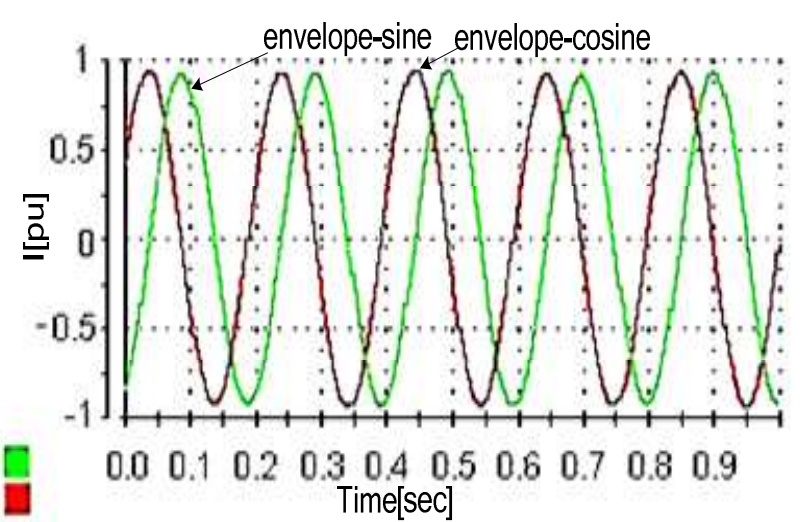

(a)

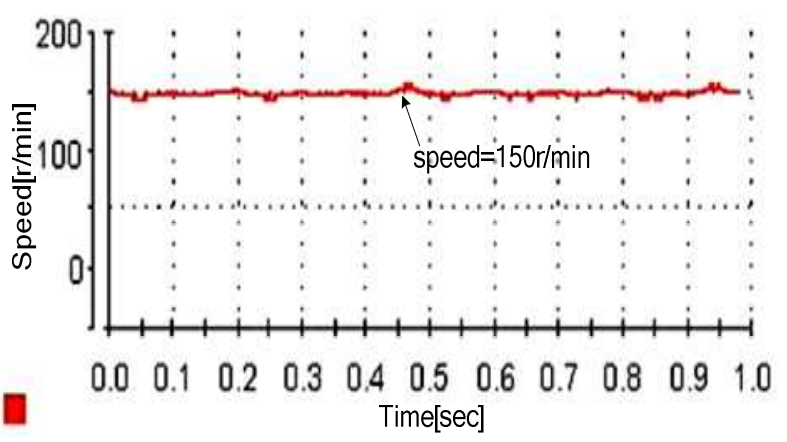

(b)

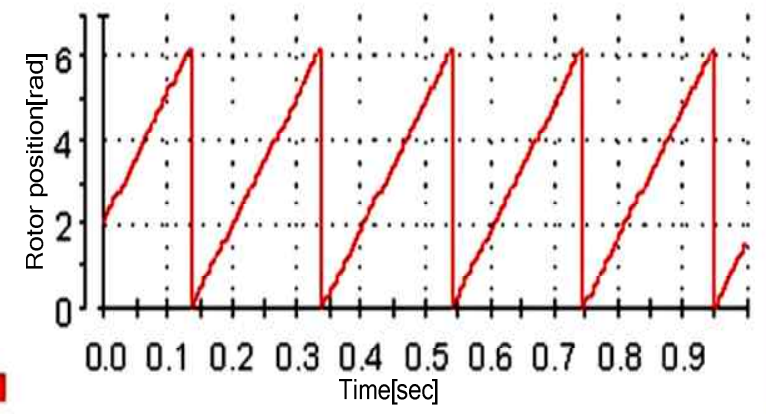

(c)

Fig. 14. Sensorless control results based on high-frequency signal injection into the stator at speed of $150 \mathrm{r} / \mathrm{min}$.

It can been seen in Figure 14 (a) that the method proposed in this paper can demodulate the inductive high frequency signals well. From Figure 14 (b) and Figure 14 (c), it can be seen that the estimated position and speed based on a HF injection are accurate. It can also be seen that high performance sensorless vector control can be realized. In the experiment, an error is unavoidable due to the precision of Hall sensors. There is small fluctuation in speed. However, it will not affect the control system's stability. The steady state sensorless control performance is good.

Figure 15 shows the sensorless control results based on a high-frequency signal injection into the stator at startup. At first, the motor is still, then high frequency signals are injected into $\alpha$-axis and $\beta$-axis. Correspondingly, the initial rotor position can be obtained. When a speed of $150 \mathrm{r} / \mathrm{min}$ is given at $5 \mathrm{~s}$, the 


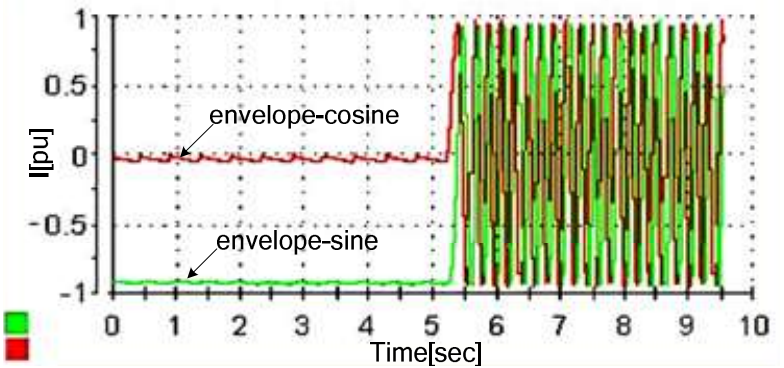

(a)

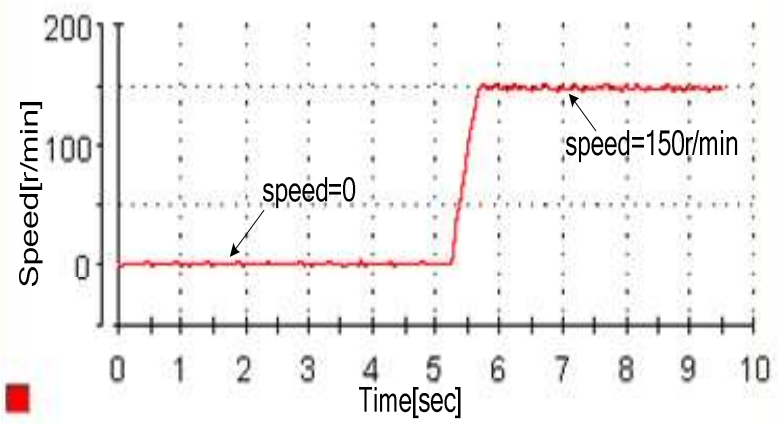

(b)

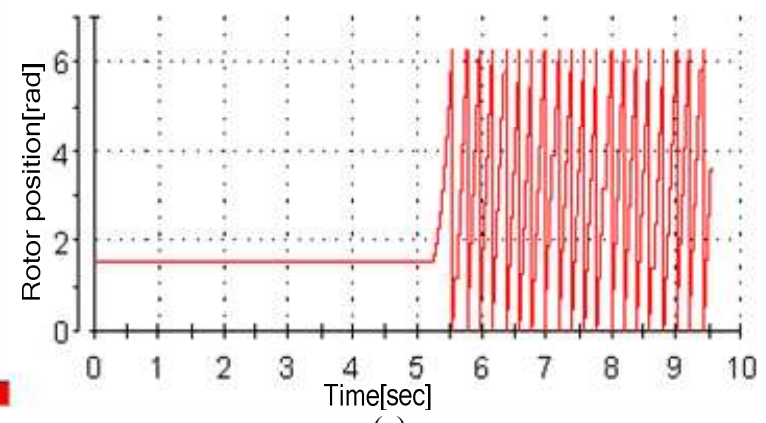

(c)

Fig. 15. Sensorless control results based on high-frequency signal injection into the stator at startup.

estimated speed follows the reference quickly and is kept steady at a given speed in a short time. The sensorless control has excellent dynamic performance. Figure 15 (a) shows the envelope of the rotor position after demodulation (the red one is cosine envelope and the blue one is the sine envelope); Figure 15 (b) shows the rotor speed; and Figure 15(c) shows the rotor position.

It can be seen in Figure 15 that the system can detect the rotor position and speed (zero) when it is at standstill. The system can quickly follow the actual speed. After adding a given speed it can follow the given speed $(150 \mathrm{r} / \mathrm{mi} n)$ quickly with the speed and position as feedback signals.

Figure 16 shows the sensorless control results based on a high-frequency signal injection into the stator while the speed is increased from $150 \mathrm{r} / \mathrm{min}$ to $210 \mathrm{r} / \mathrm{min}$. The motor rotates steadily at $150 \mathrm{r} / \mathrm{min}$ at first, then the given speed is increased to $210 \mathrm{r} / \mathrm{min}$ at $1 \mathrm{~s}$. Figure 16 (a) shows the envelope of the rotor position after demodulation (the red one is the cosine envelope

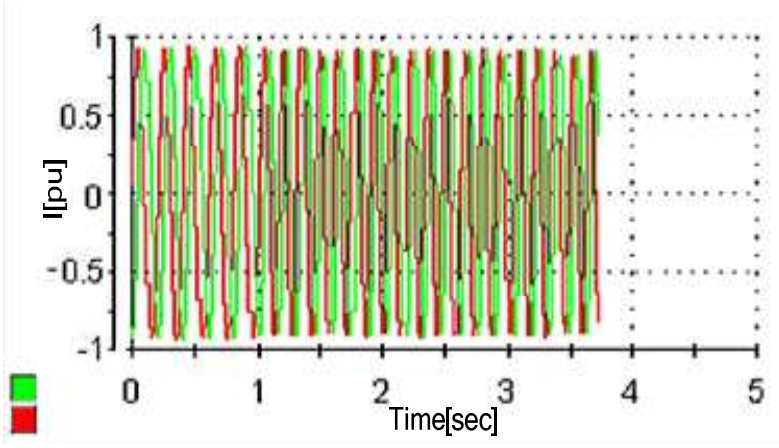

(a)

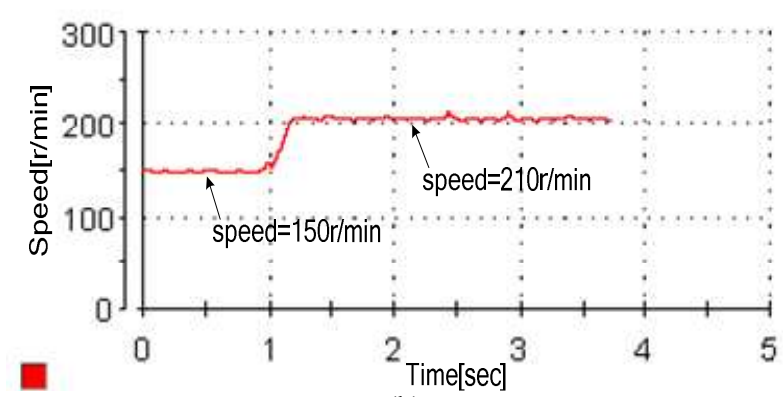

(b)

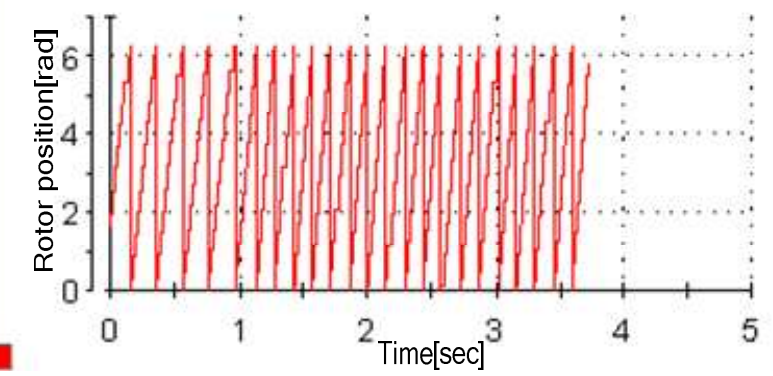

(c)

Fig. 16. Sensorless control results based on high-frequency signal injection into the stator with the speed increased from $150 \mathrm{r} / \mathrm{min}$ to $210 \mathrm{r} / \mathrm{min}$.

and the blue one is the sine envelope); Figure 16 (b) shows the rotor speed; and Figure 16 (c) shows the rotor position.

It can be seen in Figure 16 that the system can detect the actual speed and position well when the step speed is given. In addition, the motor follows the given speed (210r/min) quickly with the speed and position as feedback signals.

Based on the experimental results, it has been found that the sensorless control of a synchronous motor based on a high frequency signals injection into the stator is accurate in detecting the initial rotor position and in following the actual speed. The system has good static performance, dynamic performance and control performance.

Because of the wide measurement range of Hall sensors, they cannot detect high frequency signals when they are small. High frequency signals with a higher amplitude and a lower frequency are injected in the experiment, in order to decrease the high frequency leakage impedance and to increase the output amplitude, which makes detection by sensor easier. In 
TABLE I

PARAMETERS OF THE SM1 Machine

\begin{tabular}{|c|c|c|}
\hline Rated power & $\mathrm{P}_{\mathrm{N}}$ & $1250 \mathrm{~kW}$ \\
\hline Rated Voltage & $\mathrm{U}_{\mathrm{N}}$ & $1460 \mathrm{~V}$ \\
\hline $\begin{array}{c}\text { Rated field } \\
\text { Voltage }\end{array}$ & $\mathrm{U}_{\mathrm{fN}}$ & $78 \mathrm{~V}$ \\
\hline Rated speed & $\mathrm{n}_{\mathrm{N}}$ & $48 \mathrm{r} / \mathrm{min}$ \\
\hline Stator Resistance & $\mathrm{R}_{\mathrm{s}}$ & $0.025 \mathrm{ohm}$ \\
\hline d-axis inductance & $\mathrm{L}_{\mathrm{d}}$ & $0.037 \mathrm{H}$ \\
\hline q-axis inductance & $\mathrm{L}_{\mathrm{q}}$ & $0.021 \mathrm{H}$ \\
\hline Rotor Resistance & $\mathrm{R}_{\mathrm{f}}$ & $0.089 \mathrm{ohm}$ \\
\hline Rotor inductance & $\mathrm{L}_{\mathrm{f}}$ & $0.0071 \mathrm{H}$ \\
\hline $\begin{array}{c}\mathrm{d}-\mathrm{axis} \text { damper } \\
\text { inductance }\end{array}$ & $\mathrm{L}_{\mathrm{kd}}$ & $0.0019 \mathrm{H}$ \\
\hline $\begin{array}{c}\text { q-axis damper } \\
\text { inductance }\end{array}$ & $\mathrm{L}_{\mathrm{kq}}$ & $0.0004 \mathrm{H}$ \\
\hline
\end{tabular}

TABLE II

PARAMETERS OF THE SM2 MACHINE

\begin{tabular}{|c|c|c|}
\hline Rated power & $\mathrm{P}_{\mathrm{N}}$ & $20 \mathrm{~kW}$ \\
\hline Rated Voltage & $\mathrm{U}_{\mathrm{N}}$ & $380 \mathrm{~V}$ \\
\hline $\begin{array}{c}\text { Rated excitation } \\
\text { Current }\end{array}$ & $\mathrm{I}_{\mathrm{fN}}$ & $6.3 \mathrm{~A}$ \\
\hline Rated speed & $\mathrm{n}_{\mathrm{N}}$ & $1500 \mathrm{r} / \mathrm{min}$ \\
\hline Stator Resistance & $\mathrm{R}_{\mathrm{s}}$ & $0.26 \mathrm{ohm}$ \\
\hline d-axis inductance & $\mathrm{L}_{\mathrm{d}}$ & $0.024 \mathrm{H}$ \\
\hline q-axis inductance & $\mathrm{L}_{\mathrm{q}}$ & $0.012 \mathrm{H}$ \\
\hline Rotor Resistance & $\mathrm{R}_{\mathrm{f}}$ & $4.80 \mathrm{hm}$ \\
\hline Rotor inductance & $\mathrm{L}_{\mathrm{f}}$ & $0.0022 \mathrm{H}$ \\
\hline $\begin{array}{c}\text { d-axis damper } \\
\text { inductance }\end{array}$ & $\mathrm{L}_{\mathrm{kd}}$ & $0.0030 \mathrm{H}$ \\
\hline $\begin{array}{c}\text { q-axis damper } \\
\text { inductance }\end{array}$ & $\mathrm{L}_{\mathrm{kq}}$ & $0.0021 \mathrm{H}$ \\
\hline
\end{tabular}

addition, due to the higher amplitude of the high frequency signal, there is a large torque fluctuation in the motor which results in a small fluctuation in speed.

From the experimental results in can be seen that the method proposed in this paper realizes the sensorless control of synchronous motors well. However, there are still some disadvantages. The high frequency signal is much smaller than the fundamental frequency signal. As a result, how to pick up and filter the signal accurately before industry application still needs to be studies.

\section{CONCLUSIONS}

The mechanical sensor in WRSM drive systems is necessary to realize high performance vector control. However, it is difficult to install and maintain such sensors. Sensorless control technology is the fundamental way to solve the above problems.
According to the special structure and electromagnetic characteristics of WRSMs, a sensorless method with rotor speed and position detection based on a high frequency signal injection into the stator is proposed in this paper. An effective demodulation method for the inductive high frequency in the rotor side is proposed as well. The estimated position and speed signals can be used for vector control directly. Simulation and experimental results prove that the proposed method is a promising approach for industry application.

\section{ACKNOWLEDGMENT}

This work was supported by the Fundamental Research Funds for the Central Universities (China University of Mining and Technology) (2010ZDP01A10).

\section{REFERENCES}

[1] S. Kerneth and R. Taylor, "Sensorless velocity control of permanent-magnet synchronous motors Control Systems Technology," IEEE Trans. Contr. Syst. Technol., Vol. 6, No. 3, pp. 313-324, May 1998.

[2] M. E. Elbuluk and L. I. Changsheng, "Sliding mode observer for wide-speed sensorless control of PMSM drives,"in Industry Applications Conference, 2003._38 $8^{\text {th }}$ IAS Annual Meeting, Vol.1, pp.480-485,12-16 Oct.2003.

[3] C. Zhiqian, T. Mutuwo, D. Shiniji, and O. Shigeru, "An extended electromotive force model for sensorless control of interior permanent-magner synchronous motors," IEEE Trans. Ind. Electron., Vol. 50, No. 2, pp. 288-295, Apr. 2003.

[4] L. Idkhajine, E. Monmasson, and A. Maalouf, "Fully FPGA-based sensorless control for AC drive using an extended kalman filter," in IEEE-IECON 2009, pp. 2925-2930, Nov.2009.

[5] D. Rached, M. Ned, and N. L. Einar, "Design and implementation of an extended Kalman filter for the state estimation of a permanent magnet synchronous motor," IEEE Trans. Power Electron., Vol. 6, No. 3, pp. 491-497, Jul.1991.

[6] B. Silverio, Z. Mauro, and Z. Marco, "Extended-range PMSM Sensorless Speed Drive Based on Stochastic Filtering," IEEE Trans. Power Electron., Vol.16, No.1, pp. 110-117, Jan. 2001.

[7] M. Zhixun, K. Ralph, and M. Ralph, "System-on-Chip sensorless control of PMSM combining signal injection and flux observer," in IEEE $7^{\text {th }}$ International Power Electronics and Motion Control Conference-ECCE Asia, Vol. 2, pp. 1201-1205, Jun. 2012.

[8] X. Deng, L. Wang, J. Zhang, and K. Wang, "Design and finite element analysis of a novel structure brushless synchronous machine," International Journal of Applied Electromagnetics and Mechanics, Vol.33, pp. 127-133, 2010.

[9] L. A. S. Ribeiro, M. W. Degner, F. Briz, and R. D. Lorenz, "Comparison of carrier signal voltage and current injection for the estimation of flux angle of rotor position," in Thirty-Third IAS Annual Meeting of IEEE, Vol.1, pp. 452-459, Oct.1998. 
[10] Y.-S. Jeong, R. D. Lorenz, T. M. Jahns, and S.-K. Sul, "Initial rotor position estimation of an interior permanent magnet synchronous machine using carrier-frequency injection methods," IEEE Trans. Ind. Appl., Vol. 41, No. 1, pp. 38-45, Jan. 2005.

[11] P. Vadstrup and R. D. Lorenz, "Robust estimator design for signal injection-based IPM synchronous machine drives," in Conference Record of the 39th IAS Annual Meeting, Vol.2, pp. 957-963,3-7 Oct. 2004.

[12] L. Wang, X. Deng, R. Wang, and K. Huang, "Rotor position and speed detection of synchronous motor without mechanical sensor," Electric Machines and Control, Vol. 16, No. 5, pp. 57-62, May 2012.

[13] A. Bellini and S. Bifaretti, "A digital filter for speed noise reduction in drives using an electromagnetic resolver," Mathematics and Computers in Simulation, No. 17, pp. 476-486, 2006.

[14] Z. Xu, M. F. Rahman, G. Wang, and D. Xu, "Performance evaluation of an integrated Starter -Alternator with an IPM synchronous machine under sensor-less operation," Journal of Power Electronic, Vol. 12, No. 1, pp. 49-57, Jan. 2012.

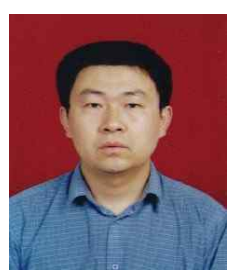

Zhiguo Chen was born in Shanxi, China, in 1971. He received his B.S. in Electrical Engineering from the China University of Mining and Technology, Xuzhou, China, in 1993. He is currently working towards his Ph.D. in the School of Information and Electrical Engineering, China University of Mining and Technology. Since 2009, he has been with the School of Information and Electrical Engineering, China University of Mining and Technology, as an Associate Professor. His current research interests include power electronics and motor drives.

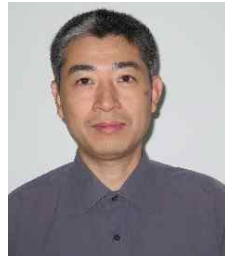

Xianming Deng was born in Sichuan, China, in 1970. He received his Ph.D. in Electrical Engineering from the China University of Mining and Technology, Xuzhou, China, in 2007. Since 2008, he has been a Professor with the School of Information and Electrical Engineering, China University of Mining and Technology. His current research interests include electric machine design and motor drives.

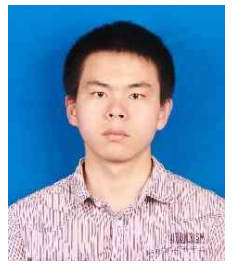

Kun Huang was born in Hubei, China, in 1990. He received his B.S. in Electrical Engineering and Automation from the China University of Mining and Technology, Xuzhou, China, in 2010. He is currently working toward his M.S. in the School of Information and Electrical Engineering, China University of Mining and Technology. His current research interests include PMSM drives and sensorless control of synchronous motors.

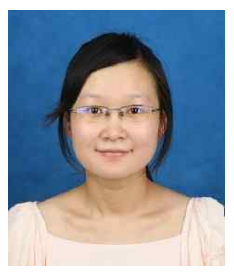

Wenhuan Zhen was born in Jiangsu, China, in 1988. She received her B.S. in Electrical Engineering and Automation from the China University of Mining and Technology, Xuzhou, China, in 2011. She is currently working towards her M.S. in the School of Information and Electrical Engineering, China University of Mining and Technology. Her current research interests include electric machine design and magnetic field analysis using the finite element method.

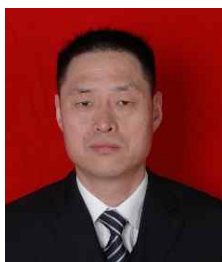

Lei Wang was born in Henan, China, in 1972. He received his Ph.D. in Electrical Engineering from the China University of Mining and Technology, Xuzhou, China, in 2012. His current research interests include power electronics and motor drives. 